\title{
Application of the Fuzzy Multi-criteria Decision-Making Method to Identify Nonlinear Decision Models
}

\author{
Wojciech Sałabun \\ Department of Artificial Intelligence Methods and Applied Mathematics, \\ Faculty of Computer Science and Information Technology, \\ West Pomeranian University of Technology, Szczecin, Poland.
}

\begin{abstract}
A large number of multi-criteria methods have been developed to deal with different kinds of problems. Most of them use a linear aggregation, what is the cause of many shortcomings in solving decision problems. This paper presents how to identify nonlinear multi-criteria decision-making models with using the new fuzzy method: the Characteristic Objects Method $(C O M E T)$. In this approach, models are constructed on the basis of characteristic objects and fuzzy rules. Thereby, the COMET method is free of rank reversal phenomenon, which is one of the most commonly indicated shortcoming of the multi-criteria decisionmaking methods. This study introduces the concepts of characteristic objects and way of their determination. Subsequently, the paper presents approach to construct the fuzzy rule base and the entire model. Finally, the theoretical nonlinear problem is presented to verify the developed approach and to demonstrate its effectiveness.
\end{abstract}

\section{General Terms:}

Decision support

\section{Keywords:}

Multi-criteria Making-decision Method, Rank Reversal, Decision Making, Characteristic Objects, COMET Method

\section{INTRODUCTION}

In the complex world, the human decisions are not always correct and successful [1]. It is mostly caused by the fact that many decision problems involve a large number of conflicted objectives [2, 3]. This problem relates primarily to nonlinear problems, which are more difficult to solve than linear problems [4]. The multi-criteria decision-making methods were created to cope with these problems. For instance, the commonly used methods are: Simple Additive Weighting $(S A W)$ [9, 10, 11, 12, 13, 14], the Analytic Hierarchy Process $(A H P)$ [15] 16, 17, 18, 19, 20, 21, 22, 23], Technique for Order of Preference by Similarity to Ideal Solution (TOPSIS) [24, 25, 26, 27, 28, 29, 30], Elimination and Choice Expressing Reality $(E L E C T R E)$ family methods [31, 32, 33, 34, 35] and PROMETHEE [36, 37, 38, 39]. These approaches cope well with the linear problems, however, the rank reversal phenomenon is occurred for nonlinear problems. The commonly used rank reversal definition emphasizes that this issue occurs when the rankings for the alternatives are changed with either the addition of or removal of an alternative. As the result, decision-makers cannot be sure, which ranking is correct. The process of evaluating is not connected with alternatives in the COMET method, so it is completely rank reversal free approach. The evaluating model is created by using invariable points, which are called characteristic objects.

In section 2, the basic concepts and operations related to the fuzzy set theory are given. In section 3, the concept of the characteristic objects is introduced. Then, the COMET method is presented, which is the new fuzzy multi-criteria decision-making method. The basis of this approach was developed by professor Piegat [4]. In section 4 , the theoretical nonlinear problem is presented to verify the proposed approach. In section 5, the effectiveness of the $C O M E T$ method is discussed on the basis of model from previous section. The conclusions are presented in section 6 .

\section{FUNDAMENTAL NOTIONS AND CONCEPTS OF THE FUZZY SETS}

Hereafter, the essential concepts of fuzzy sets are introduced, which are using in the COMET method. This section is focused on the fundamental ideas, i.e., fuzzy set, membership function, triangular fuzzy numbers, the support and core of a triangular fuzzy number, fuzzy rule, the rule base and T-norm operator.

Definition 1 Fuzzy set and membership function.

The characteristic function $\mu_{A}$ of a crisp set $A \subseteq X$ assigns a value either 0 or 1 to each member in $X$ inasmuch as crisp sets only allow full membership $\left(\mu_{A}(x)=1\right)$ or non-membership at all $\left(\mu_{A}(x)=0\right)$. This function can be generalized to a function $\mu_{\tilde{A}}$ such that the value assigned to the element of the universal set $X$ fall within a specified range, i.e., $\mu_{\tilde{A}}: X \rightarrow[0,1]$. The assigned value indicates the membership grade of the element in the set $\mathrm{A}$. The function $\mu_{\tilde{A}}$ is called the membership function and the set $\tilde{A}=\left\{\left(x, \mu_{\tilde{A}}(x)\right)\right\}$, where $x \in X$, defined by $\mu_{\tilde{A}}(x)$ for each $x \in X$ is called a fuzzy set [5, 6, 7].

Definition 2 Triangular fuzzy number (TFN).

A fuzzy set $\tilde{A}$, defined on the universal set of real numbers $\Re$, is said to be a triangular fuzzy number $\tilde{A}(a, m, b)$ if its membership 
function has the following form (1] [1]:

$$
\mu_{\tilde{A}}(x, a, m, b)= \begin{cases}0 & x \leq a \\ \frac{x-a}{m-a} & a \leq x \leq m \\ 1 & x=m \\ \frac{b-x}{b-m} & m \leq x \leq b \\ 0 & x \geq b\end{cases}
$$

and the following characteristics (2, 3):

$$
\begin{aligned}
& x_{1}, x_{2} \in[a, b] \wedge x_{2}>x_{1} \Rightarrow \mu_{\tilde{A}}\left(x_{2}\right)>\mu_{\tilde{A}}\left(x_{1}\right) \\
& x_{1}, x_{2} \in[b, c] \wedge x_{2}>x_{1} \Rightarrow \mu_{\tilde{A}}\left(x_{2}\right)<\mu_{\tilde{A}}\left(x_{1}\right)
\end{aligned}
$$

Definition 3 The support of a TFN $\tilde{A}$

This is the crisp subset of the set $\tilde{A}$ whose all elements have nonzero membership values in the set $\tilde{A}(4)$ :

$$
S(\tilde{A})=\left\{x: \mu_{\tilde{A}}(x)>0\right\}=[a, b]
$$

Definition 4 The core of a TFN $\tilde{A}$

This is the singleton (one-element fuzzy set) with the membership value equal to one (5):

$$
C(\tilde{A})=\left\{x: \mu_{\tilde{A}}(x)=1\right\}=m
$$

Definition 5 The fuzzy rule

The single fuzzy rule can be based on tautology Modus Ponens [6 8]. The reasoning process uses logical connectives $I F-T H E N, O R$ and $A N D$.

Definition 6 The rule base.

The rule base consists of logical rules determining causal relationships existing in the system between fuzzy sets of its inputs and output [40].

Definition 7 T-norm operator: product.

The $\mathrm{t}$-norm operator is a function $\mathrm{T}$ modeling the intersection operation AND of two or more fuzzy numbers, e.g. $\tilde{A}$ and $\tilde{B}$. In this paper, only product is used as t-norm operator [6, 8, 40] (6):

$$
\mu_{\tilde{A}}(x) A N D \mu_{\tilde{B}}(y)=\mu_{\tilde{A}}(x) \cdot \mu_{\tilde{B}}(y)
$$

\section{THE CHARACTERISTIC OBJECTS METHOD (COMET)}

The COMET method is a very simple approach, but to be able to understand better this technique, the basic knowledge on the Fuzzy Sets is necessary [4, 41]. The formal notation of COMET method is presented below in the five following subsections.

\subsection{Define the space of the problem}

An expert determines dimensionality of the problem by selecting number $r$ of criteria, $C_{1}, C_{2}, \ldots, C_{r}$. Subsequently, the set of triangular fuzzy numbers for each criterion $C_{i}$ is selected, i.e., $\tilde{C}_{i 1}, \tilde{C}_{i 2}, \ldots, \tilde{C}_{i c_{i}}$. In this way, the following result is obtained 77 :

$$
\begin{aligned}
& C_{1}=\left\{\tilde{C}_{11}, \tilde{C}_{12}, \ldots, \tilde{C}_{1 c_{1}}\right\} \\
& C_{2}=\left\{\tilde{C}_{21}, \tilde{C}_{22}, \ldots, \tilde{C}_{2 c_{1}}\right\} \\
& \ldots \ldots \ldots \ldots \ldots \ldots \ldots \ldots \ldots \ldots \ldots \ldots \ldots \ldots \ldots \ldots \ldots \ldots \ldots \ldots \ldots \ldots \ldots \\
& C_{r}=\left\{\tilde{C}_{r 1}, \tilde{C}_{r 2}, \ldots, \tilde{C}_{r c_{r}}\right\}
\end{aligned}
$$

where $c_{1}, c_{2}, \ldots, c_{r}$ are numbers of the fuzzy numbers for all criteria.

\subsection{Generate the characteristic objects}

The characteristic objects $(C O)$ are obtained by using the Cartesian Product of triangular fuzzy numbers cores for each criteria as follows (8):

$$
C O=C\left(C_{1}\right) \times C\left(C_{2}\right) \times \ldots \times C\left(C_{r}\right)
$$

As the result of this, the ordered set of all $C O$ is obtained (9):

$$
\begin{aligned}
& C O_{1}=C\left(\tilde{C}_{11}\right), C\left(\tilde{C}_{21}\right), \ldots, C\left(\tilde{C}_{r 1}\right) \\
& C O_{2}=C\left(\tilde{C}_{11}\right), C\left(\tilde{C}_{21}\right), \ldots, C\left(\tilde{C}_{r 2}\right) \\
& \ldots \ldots \ldots \ldots \ldots \ldots \ldots \ldots \ldots \ldots \ldots \ldots \ldots \ldots \ldots \\
& C O_{t}=C\left(\tilde{C}_{1 c_{1}}\right), C\left(\tilde{C}_{2 c_{2}}\right), \ldots, C\left(\tilde{C}_{r c_{r}}\right)
\end{aligned}
$$

where $t$ is a number of $C O$ (10):

$$
t=\prod_{i=1}^{r} c_{i}
$$

\subsection{Rank the characteristic objects}

The expert determines the Matrix of Expert Judgment $(M E J)$. It is a result of comparison of the characteristic objects by the knowledge of expert. The $M E J$ structure is as follows (11):

$$
M E J=\left(\begin{array}{cccc}
\alpha_{11} & \alpha_{12} & \ldots & \alpha_{1 t} \\
\alpha_{21} & \alpha_{22} & \ldots & \alpha_{2 t} \\
\ldots & \ldots & \ldots & \ldots \\
\alpha_{t 1} & \alpha_{t 2} & \ldots & \alpha_{t t}
\end{array}\right)
$$

where $\alpha_{i j}$ is a result of comparing $C O_{i}$ and $C O_{j}$ by the expert The more preferred characteristic object gets one point and the second object get zero point. If the preferences are balanced, the both objects get half point. It depends solely on the knowledge of the expert and can be presented as (12):

$$
\alpha_{i j}=\left\{\begin{array}{l}
0.0, f_{\text {exp }}\left(C O_{i}\right)<f_{\text {exp }}\left(C O_{j}\right) \\
0.5, f_{\text {exp }}\left(C O_{i}\right)=f_{\text {exp }}\left(C O_{j}\right) \\
1.0, f_{\text {exp }}\left(C O_{i}\right)>f_{\text {exp }}\left(C O_{j}\right)
\end{array}\right.
$$

where $f_{\exp }$ is an expert judgment function. The most important properties are described by equations $(13)$ and $(14)$ :

$$
\begin{gathered}
\alpha_{i i}=0.5 \\
\alpha_{j i}=1-\alpha_{i j}
\end{gathered}
$$

On the basis of (13) and (14), the number of comparisons is reduced from $t^{2}$ cases to $p$ cases 15 :

$$
p=\left(\begin{array}{c}
t \\
2
\end{array}\right)=\frac{t(t-1)}{2}
$$

Afterwards, the vertical vector of the summed Judgments $(S J)$ is obtained as follows $[16$ :

$$
S J_{i}=\sum_{j=1}^{t} \alpha_{i j}
$$

The last step assigns to each characteristic object the approximate value of preference. In the result, the vertical vector $P$ is obtained, where $i-t h$ row contains the approximate value of preference for $C \mathrm{O}_{i}$. This algorithm is presented as a fragment of Matlab code:

1: $\mathrm{k}=$ length (unique $(\mathrm{SJ})$ );

2: $\mathrm{P}=\operatorname{zeros}(t, 1)$; 


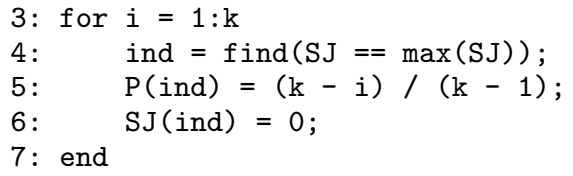

In line 1 , the number $\mathrm{k}$ is obtained as a number of unique value of the vector $S J$. In line 2 , the vertical vector $\mathrm{P}$ of zeros is created (with identical size as vector $S J$ ). In line 4 , the index with maximum value from vector $S J$ is obtained. This index is used to assign the value of preference to adequate position in vector $P$ (based on the principle of indifference of Laplacea). In line 6, the maximum value of the vector $S J$ is reset.

\subsection{The rule base}

Each one characteristic object and value of preference is converted to a fuzzy rule as follows, general form (17) and detailed form 18:

$$
\text { IF } C_{i} \text { THEN } P_{i}
$$

$$
\text { IF } C\left(\tilde{C}_{1 i}\right) \text { AND } C\left(\tilde{C}_{2 i}\right) \text { AND } \ldots \text { THEN } P_{i}
$$

In this way, the complete fuzzy rule base is obtained (19):

$$
\begin{array}{llll}
I F & C O_{1} & \text { THEN } & P_{1} \\
\text { IF } & C O_{2} & \text { THEN } & P_{2} \\
\ldots & \ldots & \ldots & \ldots \\
I F & C O_{t} & \text { THEN } & P_{t}
\end{array}
$$

\subsection{Inference and final ranking}

The each one alternative is a set of crisp number, which corresponding with criteria $C_{1}, C_{2}, \ldots, C_{r}$. It can be presented as follows 20]:

$$
A_{i}=\left\{a_{1 i}, a_{2 i}, \ldots, a_{r i}\right\}
$$

where condition 21] must be satisfied.

$$
\begin{aligned}
& a_{1 i} \in\left[C\left(\tilde{C}_{11}\right), C\left(\tilde{C}_{1 c_{1}}\right)\right] \\
& a_{2 i} \in\left[C\left(\tilde{C}_{21}\right), C\left(\tilde{C}_{2 c_{2}}\right)\right] \\
& \ldots \ldots \ldots \ldots \ldots \ldots \ldots \ldots \ldots \ldots \ldots \ldots \ldots \ldots \ldots \ldots \ldots \ldots \ldots \ldots \ldots \ldots \ldots \ldots \\
& a_{r i} \in\left[C\left(\tilde{C}_{r 1}\right), C\left(\tilde{C}_{r c_{r}}\right)\right]
\end{aligned}
$$

Each one alternative activates the specified number of fuzzy rules, where for each one is determined the fulfillment degree of the conjunctive complex premise. Fulfillment degrees of all activated rules sum to one. The preference of alternative is computed as sum of the product of all activated rules, as their fulfillment degrees, and their values of the preference. The final ranking of alternatives is obtained by sorting the preference of alternatives.

\section{EXPERIMENT AND RESULTS}

In most cases of used $M C D M$ methods, decision-makers cannot be sure whether the resulting ranking is correct. Moreover, if decision-makers get two conflicted rankings, one of them is certainly incorrect. This issue lies in heart every multi-criteria decision-making methods. The theoretical nonlinear problem is given to examine the effectiveness of proposed approach, because the strong reference is needed to do it. Therefore, the mathematical formula will be used instead of expert. This assumption eliminates purely human errors, and allows to validate the method. Lets consider a nonlinear problem with only two criteria. The solution will be the three-dimensional surface, which can be presented in an illustration. The reference formula of this problem is presented as

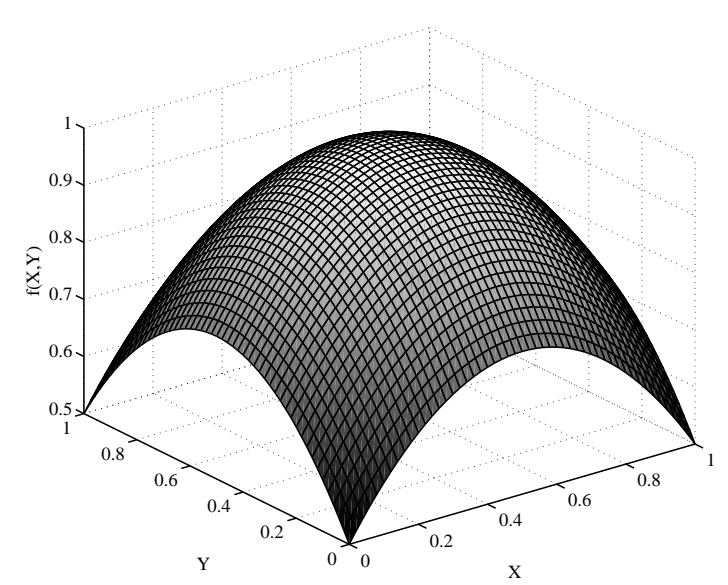

Fig. 1. The shape of the reference function.

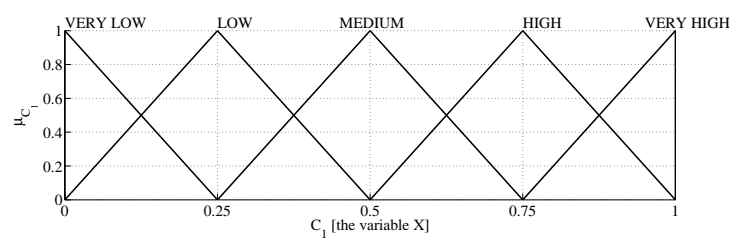

Fig. 2. Membership functions for the criterion $C_{1}$.

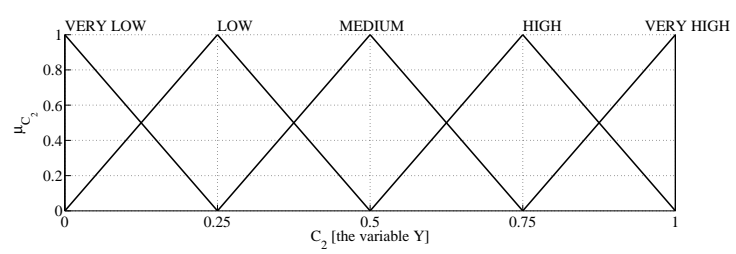

Fig. 3. Membership functions for the criterion $C_{2}$.

22):

$$
f(X, Y)=1-(X-0.5)^{2}-(Y-0.5)^{2}
$$

where the variable $\mathrm{X}$ is the first criterion and variable $\mathrm{Y}$ is the second criterion. The both variables are considered in the interval from zero to one. Figure 1 presents shape of this function.

The space of the problem is defined using two criterion (23), where each of them is presented as the set of five equal division triangular fuzzy numbers (see figure 2 and figure 3 .

$$
\begin{aligned}
& C_{1}=\left\{\tilde{C}_{11}, \tilde{C}_{12}, \tilde{C}_{13}, \tilde{C}_{14}, \tilde{C}_{15}\right\} \\
& C_{1}=\left\{\tilde{C}_{21}, \tilde{C}_{22}, \tilde{C}_{23}, \tilde{C}_{24}, \tilde{C}_{25}\right\}
\end{aligned}
$$

The characteristic objects are obtained on the basis these triangular fuzzy numbers and the following formula (24):

$$
C O=C\left(C_{1}\right) \times C\left(C_{2}\right)
$$

On this basis, 25 characteristic objects are obtained, which equally divide the space of the problem. Figure 4 shows all characteristic objects and their distribution.

In the next step, the 25 characteristic objects are ranked, where the $M E J$ matrix is created on the basis equations (12) and 22). The 


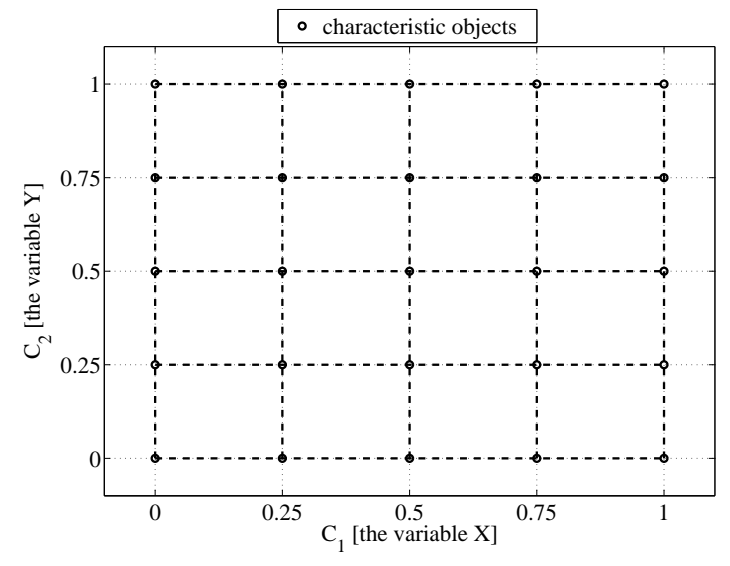

Fig. 4. Two-dimensional domain of the theoretical problem, with marked characteristic objects.

Table 1. Preference values of the characteristic objects

\begin{tabular}{|c|c|c|c||c|c|c|c|}
\hline$C O_{i}$ & $C\left(C_{1}\right)$ & $C\left(C_{2}\right)$ & $P_{i}$ & $C O_{i}$ & $C\left(C_{1}\right)$ & $C\left(C_{2}\right)$ & $P_{i}$ \\
\hline 1 & 0.00 & 0.00 & 0.0 & 14 & 0.50 & 0.75 & 0.8 \\
\hline 2 & 0.00 & 0.25 & 0.2 & 15 & 0.50 & 1.00 & 0.4 \\
\hline 3 & 0.00 & 0.50 & 0.4 & 16 & 0.75 & 0.00 & 0.2 \\
\hline 4 & 0.00 & 0.75 & 0.2 & 17 & 0.75 & 0.25 & 0.6 \\
\hline 5 & 0.00 & 1.00 & 0.0 & 18 & 0.75 & 0.50 & 0.8 \\
\hline 6 & 0.25 & 0.00 & 0.2 & 19 & 0.75 & 0.75 & 0.6 \\
\hline 7 & 0.25 & 0.25 & 0.6 & 20 & 0.75 & 1.00 & 0.2 \\
\hline 8 & 0.25 & 0.50 & 0.8 & 21 & 1.00 & 0.00 & 0.0 \\
\hline 9 & 0.25 & 0.75 & 0.6 & 22 & 1.00 & 0.25 & 0.2 \\
\hline 10 & 0.25 & 1.00 & 0.2 & 23 & 1.00 & 0.50 & 0.4 \\
\hline 11 & 0.50 & 0.00 & 0.4 & 24 & 1.00 & 0.75 & 0.2 \\
\hline 12 & 0.50 & 0.25 & 0.8 & 25 & 1.00 & 1.00 & 0.0 \\
\hline 13 & 0.50 & 0.50 & 1.0 & $\mathrm{X}$ & $\mathrm{X}$ & $\mathrm{X}$ & $\mathrm{X}$ \\
\hline
\end{tabular}

value of preference is determined as the vector $P$. The summary of this step is presented in table 1.

Finally, each one characteristic object (from table 1) is converted to a fuzzy rule. In this way, the complete fuzzy rule base is created as

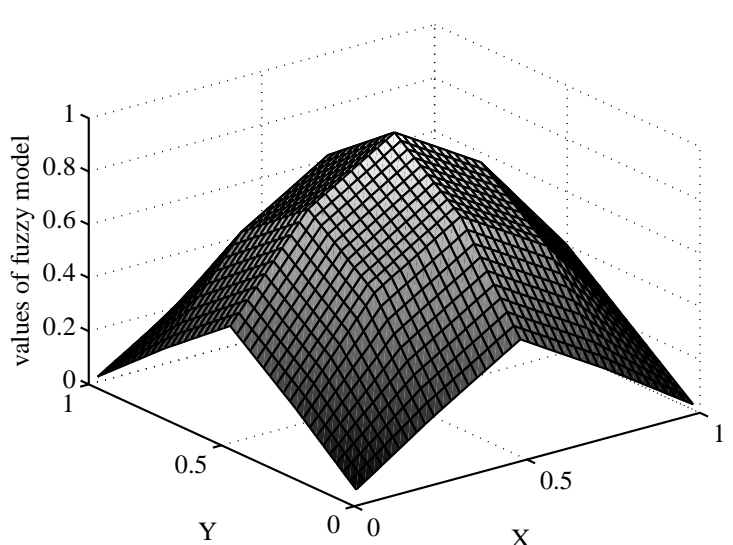

Fig. 5. The shape of the fuzzy model.

following:

\begin{tabular}{|c|c|c|c|c|}
\hline$I F \quad\left(C_{1} \sim 0\right.$ & & $\left(C_{2}\right.$ & & \\
\hline$I F \quad\left(C_{1} \sim 0\right.$ & $\mathrm{v} D$ & $\left(C_{2} \sim\right.$ & & \\
\hline$F \quad\left(C_{1} \sim 0\right.$ & $A N D$ & $\left(C_{2} \sim\right.$ & $E N$ & \\
\hline$F\left(C_{1} \sim 0\right.$ & $A N D$ & $\left(C_{2}\right.$ ᄀ & & \\
\hline$F\left(C_{1} \sim 0\right.$ & $A N D$ & $\left(C_{2}\right.$ & THEN & \\
\hline$\left(C_{1}\right.$ & $A N D$ & & $H E N$ & \\
\hline$F\left(C_{1} \sim 0.25\right)$ & $A N D$ & & HEN & \\
\hline$F\left(C_{1} \sim 0.25\right)$ & $N D$ & & PHEN & \\
\hline$F\left(C_{1}\right)$ & $N D$ & & $N$ & \\
\hline$\left(C_{1}\right.$ & $N D$ & & & \\
\hline & $A N D$ & & $N$ & \\
\hline & $A N D$ & & & \\
\hline & $A N D$ & & $N$ & \\
\hline 50) & & & $N$ & \\
\hline 50) & & & $N$ & \\
\hline$C_{1}$ & $N D$ & & $H E N$ & \\
\hline$C_{1}$ & ND & $\left(C_{2}\right.$ & $H E N$ & \\
\hline 5) & $N D$ & $\left(C_{2}\right.$ & $H E N$ & \\
\hline 5) & $A N D$ & $\left(C_{2}\right.$ & THEN & \\
\hline & $A N D$ & & $\Gamma H E N$ & \\
\hline & $A N D$ & & $H E N$ & \\
\hline & $A N D$ & & $H$ & \\
\hline & & & & \\
\hline & & & & \\
\hline & & & & \\
\hline
\end{tabular}

In the result of the investigation, the fuzzy reference model is identified for the theoretical multi-criteria decision-making problem defined as equation 22]. The surface of this model is presented in figure 5

\section{DISCUSSION OF THE RESULTS}

In the result of section 4, the fuzzy rule base was obtained, which represented the identified fuzzy model. On the first sight, there are quite a lot of differences between surfaces presented in figure 1 and figure 5, e.g., difference target sets or smoothness. However, for the decision-making support, a model must properly compare two alternatives. Therefore, the test sample of alternatives should be drawn to estimate percent of the correct comparisons between alternatives. The Sample size is determined by the assumed maximum error (we assume 0.001) and the confidence level, i.e., 0.9995. 
For this data, it has to draw 2,706,848 test pairs [42], which round up to tens of thousands $(2,750,000$ samples). For each one pair is checked which one is better using the fuzzy model and equation (22). If answer from the fuzzy model is correct, then a test pair is marked as success and otherwise as defeat of classification by using COMET method (success 1 , defeat 0 ). The summed number of success divided on the number of samples is the effectiveness of the identification. In this way, the effectiveness of the fuzzy modeling is estimated at $97.78 \%$. This result is very well as multi-criteria decision-making method.

\section{CONCLUSIONS}

In this paper, the traditional fuzzy modeling have been extended to the support of the multi-criteria decision-making problems. The concepts of the new fuzzy method have been presented. The COMET method is completely free from the rank reversal phenomenon, because all preferences are based on characteristic objects. Therefore, if decision-makers add or remove any number of alternatives, then the assessing of alternatives are invariable. The theoretical nonlinear problem is used to verify the developed approach and to demonstrate its effectiveness. The result show that the proposed method provides us with a useful way to deal with multi-criteria decision-making problems.

\section{REFERENCES}

[1] Pedrycz, W., Ekel, P., Parreiras, R. 2011. Fuzzy Multicriteria Decision Making: models, methods and applications. John Wiley \& Sons: Chichester.

[2] Goodwin, P., Wright, G. 2009. Decision Analysis for Management Judgment. John Wiley \& Sons: Chichester.

[3] Mosavi, A. 2014. Decision-Making in Complicated Geometrical Problems, International Journal of Computer Applications, Vol. 87, No. 19, pp. $22-25$.

[4] Piegat, A., Sałabun W. 2012. Nonlinearity of human multicriteria in decision-making, Journal of Theoretical and Applied Computer Science, Vol. 6, No. 3, pp. 36 - 49.

[5] Kaufmann, A., Gupta M. 1988. Fuzzy mathematical models in engineering and management science. Elsevier Science Publishers: Amsterdam, Netherlands.

[6] Piegat, A. 2001. Fuzzy Modeling and Control. Springer-Verlag: New York.

[7] Kumar, A., Singh, P., Kaur, A. 2010. RM Approach for Ranking of Generalized Trapezoidal Fuzzy Numbers, Fuzzy Information and Engineering, Vol. 2, No. 1, pp. 37 - 47.

[8] Wang, G., Wang, H. 2001. Non-fuzzy versions of fuzzy reasoning in classical logics, Information Sciences, Vol. 138, No. 1 4, pp. $211-236$.

[9] Afshari, A., Mojahed, M., Yusuff, R. 2010. Simple Additive Weighting approach to Personnel Selection problem. International Journal of Innovation, Management and Technology, Vol. 1, No. 5, pp. $511-515$.

[10] Salih, Y., See O., Ibrahim, R., Yussof, S., Iqbal, A. 2014. A Novel Noncooperative Game Competing Model Using Generalized Simple Additive Weighting Method to Perform Network Selection in Heterogeneous Wireless Networks. International Journal of Communication Systems, first published online: 3 FEB 2014.
[11] Huang, YS., Chang, WC., Li, WH., Lin, ZL. 2013. Aggregation of utility-based individual preferences for group decisionmaking. European Journal of Operational Research, Vol. 229, No. 2, pp. $462-469$.

[12] French, S. 2009. Decision behavior, analysis and support. Cambridge, New York.

[13] Kontos, TD., Komilis, DP., Halvadakis, CP. 2005. Siting MSW landfills with a spatial multiple criteria analysis methodology. Waste Management, Vol. 25, No. 8, pp. 818 - 832.

[14] Simanaviciene, R., Ustinovichius, L. 2010. Sensitivity analysis for multiple criteria decision making methods: TOPSIS and $S A W$. Procedia - Social and Behavioral Sciences, Vol. 2, No. 6, pp. 7743 - 7744.

[15] Blair, AR., Mandelker, GN., Saaty, TL., Whitaker, R. 2010. Forecasting the resurgence of the u.s. economy in 2010: An expert judgment approach. Socio-Economic Planning Sciences, vOL. 44, No. 3, pp. $114-121$.

[16] Dong, Y., Zhang, G., Hong, W.C., Xu, Y. 2010. Consensus models for AHP group decision making under row geometric mean prioritization method. Decision Support Systems, Vol. 49, No. 3, pp. $281-289$.

[17] Karami, E. 2006. Appropriateness of farmers adoption of irrigation methods: The application of the AHP model. Agricultural Systems Vol. 87, No. 1, pp. $101-119$.

[18] Saaty, TL. 2004. Decision making the analytic hierarchy and network processes (AHP/ANP), Journal of Systems Science and Systems Engineering, Vol. 13, No. 1, pp. 1-35.

[19] Saaty, TL. 2007. Time dependent decision-making; dynamic priorities in the AHP/ANP: Generalizing from points to functions and from real to complex variables, Mathematical and Computer Modelling Vol. 46 No. 78, pp. 860 - 891.

[20] Saaty, TL. 2008. Decision making the analytic hierarchy and network processes (AHP/ANP), International Journal Services Sciences Vol. 1, No. 1, pp. $83-98$.

[21] Saaty, TL., Brandy, C. 2009. The encyclicon, volume 2: a dictionary of complex decisions using the analytic network process. RWS Publications, Pittsburgh.

[22] Saaty, TL., Shang, JS. 2011. An innovative orders-ofmagnitude approach to AHP-based mutli-criteria decision making: Prioritizing divergent intangible humane acts, European Journal of Operational Research, Vol. 214 No. 3, pp. 703 -715 .

[23] Saaty, TL., Tran, LT. 2007. On the invalidity of fuzzifying numerical judgments in the analytic hierarchy process, Mathematical and Computer Modelling, Vol. 46, No. 78, pp. $962-$ 975.

[24] Kwanyoung, I., Hyunbo, C. 2013. A systematic approach for developing a new business model using morphological analysis and integrated fuzzy approach, Expert Systems with Applications, Vol. 40 No. 11, pp. 4463-4477.

[25] Kuo, RJ., Wu, YH., Hsu, TS. 2012. Integration of fuzzy set theory and TOPSIS into HFMEA to improve outpatient service for elderly patients in Taiwan, Journal of the Chinese Medical Association, Vol. 75, No. 7, pp. $341-348$.

[26] La Scalia, G., Aiello, G., Rastellini, C., Micale, R., Cicalese, L. 2011. Multi-criteria decision making support system for pancreatic islet transplantation, Expert Systems with Applications, Vol. 38 No. 4, pp. 3091-3097. 
[27] Taleizadeh, AA., Akhavan Niaki, ST., Aryanezhad, MB. 2009. A hybrid method of Pareto, TOPSIS and genetic algorithm to optimize multi-product multiconstraint inventory control systems with random fuzzy replenishments, Mathematical and Computer Modeling, Vol. 49 No. 5-6, pp. 1044-1057.

[28] Kim, Y., Chung, ES., Jun, SM., Kim, SU. 2013. Prioritizing the best sites for treated wastewater instream use in an urban watershed using fuzzy TOPSIS, Resources Conservation and Recycling, Vol. 73, pp. $23-32$.

[29] Sun, YF., Liang, ZS., Shan, CJ., Viernstein, H., Unger, F. 2011. Comprehensive evaluation of natural antioxidants and antioxidant potentials in Ziziphus jujuba Mill. var. spinosa (Bunge) Huex H. F. Chou fruits based on geographical origin by TOPSIS method, Food Chemistry, Vol. 124, No. 4, pp. 1612 -1619 .

[30] Sałabun, W. 2013. The mean error estimation of TOPSIS method using a fuzzy reference models, Journal of Theoretical and Applied Computer Science, Vol. 7, No. 3, pp. 40-50.

[31] Norese, MF., Carbone, V. 2013. An Application of ELECTRE Tri to Support Innovation, Journal of Multi-Criteria Decision Analysis, first published online: 20 DEC 2014.

[32] Hatami-Marbini, A., Tavana, M. 2011. An extension of the ELECTRE I method for group decision-making under a fuzzy environment, Omega, Vol. 39, No. 4, pp. 373 - 386.

[33] Brito, A.J., de Almeida, A.T., Mota, C.M. 2010. A multicriteria model for risk sorting of natural gas pipelines based on ELECTRE TRI integrating utility theory, European Journal of Operational Research, Vol. 200, No. 3, pp. 812 - 821.

[34] Montazer, G.A., Saremi, H.Q., Ramezani, M. 2009. Design a new mixed expert decision aiding system using fuzzy ELECTRE III method for vendor selection, Expert Systems with Applications, Vol. 36, No. 8, 10837 - 10847.

[35] Figueira, J., Greco, S., Ehrgott, M. 2004. Multiple Criteria Decision Analysis: State of the Art Surveys. Springer, New York.

[36] Eppe, S., De Smet, Y. 2014. Approximating Promethee IIs net flow scores by piecewise linear value functions, European Journal of Operational Research, Vol. 233, No. 3, pp. 651 - 659.

[37] Amaral, TM., Costa APC. 2014. Improving decision-making and management of hospital resources: An application of the PROMETHEE II method in an Emergency Department, Operations Research for Health Care, Vol. 3, No. 1, pp. 1 - 6.

[38] Makan, A., Mountadar, M. 2013. Sustainable management of municipal solid waste in Morocco: Application of PROMETHEE method for choosing the optimal management scheme, African Journal of Environmental and Waste Management, Vol. 1, No. 1, pp. 1 - 13.

[39] Ziolkowska, JR. Evaluating sustainability of biofuels feedstocks: A multi-objective framework for supporting decision making, Biomass and Bioenergy, Vol. 55, pp. 425 - 440.

[40] Ross, TJ. 2010. Fuzzy logic with engineering applications. John Wiley \& Sons: Chichester.

[41] Sałabun, W. 2012. The use of fuzzy logic to evaluate the nonlinearity of human multi-criteria used in decision making, Przeglad Elektrotechniczny (Electrical Review), Vol. 88, No. 10b, pp. $235-238$.

[42] Bartlett, JE., Kotrlik, JW., Higgins, CC. 2001. Chadwick C. HigginsOrganizational Research: Determining Appropriate Sample Size in Survey Research, Information Technology, Learning, and Performance Journal, Vol. 19, No. 1, pp. 43 - 50. 